\title{
Cotyledonoid dissecting leiomyoma: an uncommon form of a common disease
}

\author{
Iffat Jamal, Rakesh Kumar Gupta, Ranwir Kumar Sinha, Punam Prasad Bhadani \\ Department of Pathology, All India Institute of Medical Sciences, Phulwari Sharif, Patna, Bihar, India
}

Leiomyomas are benign uterine smooth muscle neoplasms with varied morphology that are well known to undergo secondary changes. Cotyledonoid dissecting leiomyoma is a rare and distinct form of leiomyoma that poses a diagnostic challenge for clinicians, radiologists, and pathologists and can be confused with malignant uterine neoplasms. Only a few cases have been reported so far in the literature. Here we report a case of a cotyledonoid dissecting leiomyoma in a 60-year-old woman, emphasize its gross and histological features, and provide a review of the literature.

Keywords: Uterus; Smooth muscle; Cotyledonoid; Leiomyoma

\section{Introduction}

Leiomyomas are benign smooth muscle neoplasms that arise from the myometrium and account for almost $75 \%$ of hysterectomy cases [1]. Such cases are mostly seen in women of reproductive age with a low incidence in postmenopausal age. Leiomyomas have numerous morphologies, among which cotyledonoid dissecting leiomyoma (CDL) is a very unusual form. Its rarity and unfamiliarity may lead to its misdiagnosis as a malignant tumor [2]. Here we describe a case of CDL in a post-menopausal woman who presented with lower abdominal pain and third-degree uterine prolapse and present a review of the literature.

\section{Case report}

A 60-year-old woman presented with the complaint of a 1 -year history of lower abdominal pain and third-degree uterovaginal descent. Her previous menstrual history was unremarkable. A vaginal examination revealed a bulky uterus with an ulceration on the anterior cervical lip. Ultrasonography revealed that the uterus was $7.5 \times 3.4 \mathrm{~cm}$ in size with an endometrial thickness of $4.9 \mathrm{~mm}$. Multiple uterine fibroids 2-4 cm in diameter were also noted. Both adenexa were unremarkable. A hysterectomy was performed and the specimen was sent for histopathological examination. Grossly, the cervix appeared hypertrophied and epidermidized. The endomyometrial thickness was $1.6 \mathrm{~cm}$, while the endometrial thickness was $0.4 \mathrm{~cm}$. Multiple fibroids up to $4 \times 3.5 \mathrm{~cm}$ were noted. In addition, 2 subserosal fibroids $2 \mathrm{~cm}$ and $3.5 \mathrm{~cm}$ in diameter were seen. A cut section of the largest intramural fibroid and 1 subserosal fibroid revealed a solid, grayishwhite, homogenous, and whorled appearance. The cut section of another subserosal fibroid revealed the presence of multiple grayish-white nodules (Fig. 1A). Microscopy revealed nodules of varying sizes of uniform smooth muscles arranged in interlacing and whorling fascicles with few prominent blood vessels (Fig. 1B-D). However, no signs of significant mitotic activity, nuclear atypia, or necrosis were seen. Based on the gross features and microscopic findings, a final diagnosis of CDL was made. Immunohistochemistry performed

Received: 2018.09.26. Revised: 2018.12.24. Accepted: 2019.01.02. Corresponding author: Rakesh Kumar Gupta

Department of Pathology, All India Institute of Medical Sciences, Aurangabad Rd, Phulwari Sharif, Patna, Bihar 801505, India.

E-mail: rakesh.newjobi@gmail.com

https://orcid.org/0000-0001-9031-1109

Articles published in Obstet Gynecol Sci are open-access, distributed under the terms of the Creative Commons Attribution Non-Commercial License (http://creativecommons. org/licenses/by-nc/3.0/) which permits unrestricted non-commercial use, distribution, and reproduction in any medium, provided the original work is properly cited.

Copyright $\odot 2019$ Korean Society of Obstetrics and Gynecology 


\section{Obstetrics \& Gynecology Science}

Iffat Jamal, et al. Dissecting cotyledonoid tumor

on CDL sections revealed diffuse positivity for vimentin, desmin, and smooth muscle actin, confirming the histopathological diagnosis of CDL (Fig. 2). In the present case, this rare variant of leiomyoma was associated with multiple intramural and subserosal classical leiomyomas showing features of hyaline degeneration (Fig. 3A). The endometrium was in the proliferative phase and adenomyosis was noted in the myometrium (Fig. 3B). The cervix showed features of acute and chronic cervicitis with surface ulceration and keratinization.

\section{Discussion}

Leiomyomas are the most common benign smooth muscle neoplasms of the uterus. A number of patterns of leiomyomas have been described. CDL, a very rare variant that is also
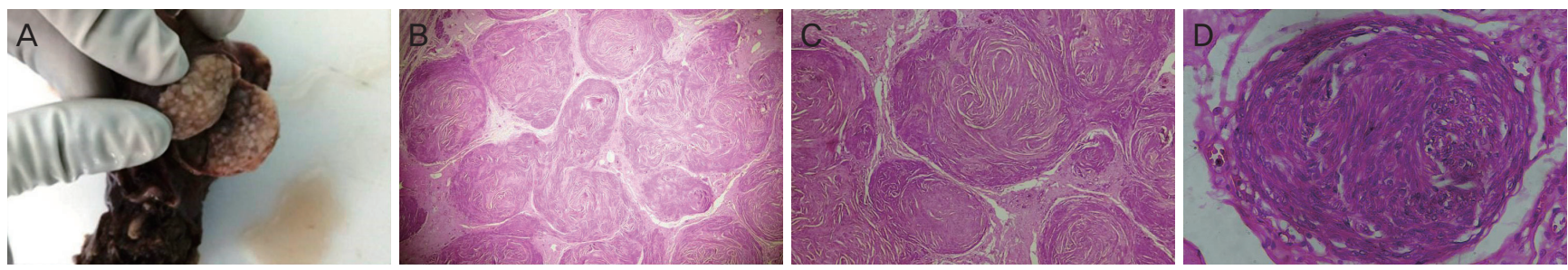

Fig. 1. Gross and histopathology images of cotyledonoid dissecting leiomyoma. (A) Cut section with multiple tan white nodules. (B) Classical whorling pattern (hematoxylin and eosin $[\mathrm{HE}], \times 20$ ). (C) Nodules of varying sizes of uniform smooth muscles arranged in interlacing and whorling fascicles with few prominent blood vessels $(\mathrm{HE}, \times 100)$. (D) Bland smooth muscles arranged in an interlacing pattern with no signs of nuclear atypia, mitosis, or necrosis $(\mathrm{HE}, \times 400)$.
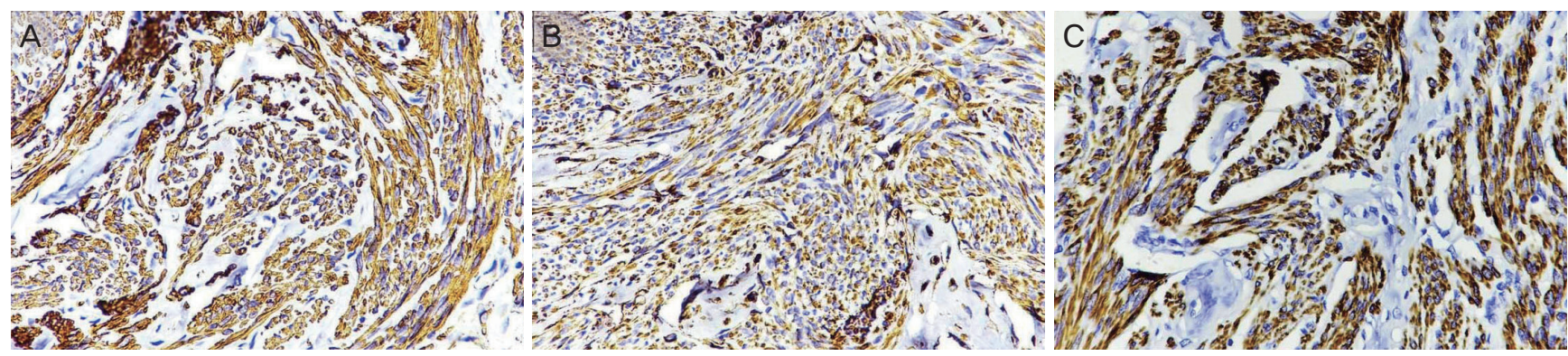

Fig. 2. Immunohistochemistry images of cotyledonoid dissecting leiomyoma showing: (A) smooth muscle actin (immunohistochemistry $[\mathrm{IHC}], \times 400)$; (B) Vimentin $(\mathrm{IHC}, \times 400)$; and (C) Desmin positivity in smooth muscle fibers $(\mathrm{IHC}, \times 400)$.
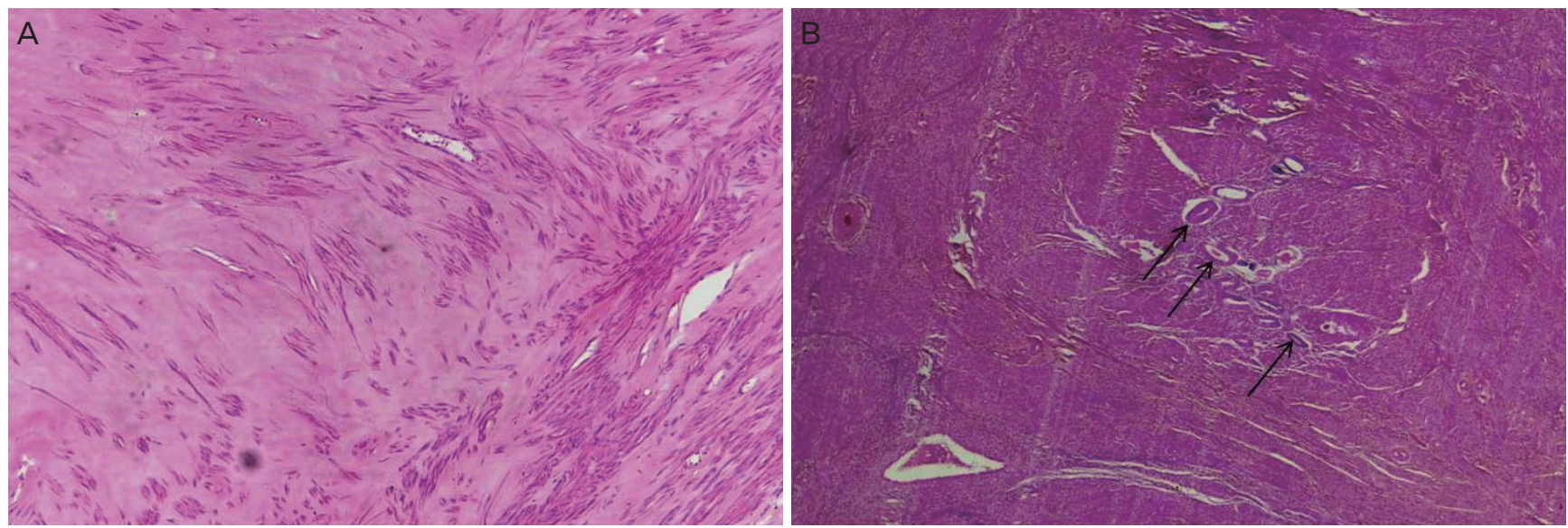

Fig. 3. Histopathological images of intramural leiomyoma showing: (A) Benign smooth muscles arranged in an interlacing pattern with large areas of hyalinization (hematoxylin and eosin $[\mathrm{HE}], \times 100)$ and myometrium; and (B) Features of adenomyosis $(\mathrm{HE}, \times 40)$. 


\section{Obstetrics \& Gynecology Science}

Vol. 62, No. 5, 2019

Table 1. Summary of the published cases of cotyledonoid dissecting leiomyoma

\begin{tabular}{|c|c|c|c|c|c|}
\hline SN & Reference & Age & Clinical presentation & $\begin{array}{c}\text { Tumor size }(\mathrm{cm}) \\
\text { maximum dimension }\end{array}$ & Tumor location \\
\hline \multirow[t]{2}{*}{1} & David et al. [1] & 65 & Abnormal uterine bleed & 15 & Uterine fundus and cervix \\
\hline & & 48 & Uterine prolapse & 12 & Uterine fundus \\
\hline \multirow[t]{4}{*}{2} & Roth et al. [2] & 39 & Pelvic mass & 10.3 & Uterine cornua \\
\hline & & 41 & Abnormal uterine bleed & 10 & Uterine cornua \\
\hline & & 23 & Pelvic mass & 25 & Uterine cornua \\
\hline & & Unknown & Pelvic mass & 24 & Uterine cornua \\
\hline 3 & Brand et al. [3] & 24 & Abdominal mass & NA & Uterine fundus \\
\hline 4 & Roth and Reed [4] & 46 & Pelvic mass & 34 & Uterine cornua \\
\hline 5 & Kim et al. [5] & 26 & Incidental & 12 & Posterior uterine wall \\
\hline 6 & Cheuk et al. [6] & 55 & Abnormal uterine bleed & 10 & Uterine cornua \\
\hline 7 & Stewart et al. [7] & 58 & Abdominopelvic mass & 16.4 & Uterine fundus \\
\hline \multirow[t]{6}{*}{8} & Jordan et al. [8] & 46 & Right adnexal mass & 22 & $\begin{array}{l}\text { Uterine with extrauterine extension } \\
\text { (all cases) }\end{array}$ \\
\hline & & 46 & Pelvic mass & 20 & \\
\hline & & 46 & Pelvic mass & 10 & \\
\hline & & 46 & Pelvic mass & 18 & \\
\hline & & 36 & Abnormal uterine bleed & 13 & \\
\hline & & 34 & Uterine mass, infertility & 18 & \\
\hline 9 & Saeed et al. [9] & 27 & Pelvic mass & 41 & Uterine fundus \\
\hline 10 & Maimoon et al. [10] & 40 & Urinary retention & 10 & Uterine isthmus \\
\hline 11 & Shelekhova et al. [11] & 73 & Uterine mass & 8 & Uterine fundus \\
\hline 12 & Gurbuz et al. [12] & 67 & Incidental & 10 & Uterine cornua \\
\hline 13 & Weissferdt et al. [13] & 52 & Abnormal uterine bleed & 6.2 & Uterine fundus \\
\hline 14 & Raga et al. [14] & 33 & Abdominal pain & 6 & Lateral part of uterus \\
\hline 15 & Driss et al. [15] & 47 & Pelvic mass & 25 & Uterine with extrauterine extension \\
\hline 16 & Preda et al. [16] & 41 & Uterine mass & 9 & Left and posterior uterine wall \\
\hline \multirow[t]{4}{*}{17} & Fukunaga et al. [17] & 56 & Constipation & 30 & Posterior uterine wall \\
\hline & & 47 & Abdominal pain & 26 & Posterior uterine wall \\
\hline & & 36 & Abnormal uterine bleed & 4 & Posterior uterine wall \\
\hline & & 35 & Abdominal pain & 18 & Lateral uterine wall \\
\hline 18 & Gezginç et al. [18] & 57 & Pelvic pain & $2.5,4.5$ & Intrauterine, lateral uterine wall \\
\hline 19 & Agarwal et al. [19] & 52 & Abnormal uterine bleeding & 10 & Uterine cornua \\
\hline 20 & Ersöz et al. [20] & 51 & Abnormal uterine bleeding & 8.5 & Subserosal \\
\hline 21 & Roth et al. [21] & 33 & Abnormal uterine bleeding & $6.5,13.5$ & Posterior uterine wall \\
\hline 22 & Tanaka et al. [22] & 36 & Incidental & 10 & Posterior \& lateral uterine wall \\
\hline 23 & Onu et al. [23] & 50 & Incidental & 10 & Uterine fundus \\
\hline 24 & Kim et al. [24] & 43 & Abdominal mass & 13 & Uterine with extrauterine extension \\
\hline 25 & Blake et al. [25] & 56 & Abnormal uterine bleeding & 30 & Uterine with extrauterine extension \\
\hline 26 & Shimizu et al. [26] & 40 & Abnormal uterine bleeding & 10 & Posterior uterine wall \\
\hline 27 & Rocha et al. [27] & 38 & Abnormal uterine bleeding & 25 & Uterine isthmus \\
\hline \multirow[t]{4}{*}{28} & Xu et al. [28] & 55 & Pelvic mass & 6 & Posterior uterine wall \\
\hline & & 43 & Pelvic mass & 3 & Body of uterus \\
\hline & & 37 & Pelvic mass & 30 & Peri- uterine \\
\hline & & 48 & Lower abdominal pain & 6.7 & Right wall of uterus \\
\hline
\end{tabular}




\section{Obstetrics \& Gynecology Science}

Iffat Jamal, et al. Dissecting cotyledonoid tumor

commonly known as Sternberg tumor, was first reported by Roth et al. [3] Menolascino-Bratta et al. [4] coined the term "angionodular dissecting leiomyoma". These tumors are frequently seen in the third to sixth decades of life. The most common complaints are lower abdominal pain and abnormal uterine bleeding. The apex case also presented with complaints of lower abdominal pain; however, no vaginal bleeding was revealed. Tumor size was typically $2-15 \mathrm{~cm}[4,5]$. Three types of CDL have been described in the literature. The first appears as an exophytic mass of multinodular tissue protruding from the lateral surface of the uterine cornua; resembling the placenta is called CDL. The second type is an intramural dissecting tumor that is confined to the uterus. These 2 types share similar histopathological features. The last type is pure cotyledonoid leiomyoma, which is not associated with either a parent intramural mass or intramural dissection [6]. This case met the criteria for exophytic CDL. Microscopically, it is characterized by nodules of various sizes of uniform smooth muscles arranged in interlacing and whorling fascicles. Many blood vessels are also prominent with focal hypercellular areas. However, in contrast to malignant lesions, signs of mitotic activity, nuclear atypia, cellular pleomorphism, and necrosis are absent. Vascular invasion, capsular infiltration, and metastasis are not seen. In a few cases, perinodular hydropic changes may be prominent [7].

A variety of other unusual patterns of uterine leiomyoma have been described, such as parasitic leiomyoma, cellular leiomyoma, symplastic or bizarre leiomyoma, epithelioid leiomyoma, intravenous leiomyomatosis, and leiomyoma with secondary changes. Some CDL appear as large fungating masses with widespread extension into the broad ligament and pelvic cavity. Due to its rarity and a clinician's lack of familiarity, such tumors are sometimes misdiagnosed as malignancies [8].

Gurbuz et al. [9] reported a case of cotyledonoid leiomyoma that had no intrauterine portion but had extrauterine extensions. A comparative analysis of various CDL cases reported in the literature is given in Table 1 and Supplementary Data 1.

In conclusion, CDL is a unique and rare variant of leiomyoma with a characteristic gross nodular appearance and microscopic features. Increasing awareness among clinicians and pathologists regarding this rare entity will prevent inappropriate diagnosis and treatment.

\section{Conflict of interest}

No potential conflict of interest relevant to this article was reported.

\section{Ethical approval}

The study was done in adherence to the Institutional Ethics committee guidelines (All India Institute of Medical Sciences, Patna, Bihar, India). As the study is purely based on tissue sample and slides which were used after routine reporting and no clinical/drug trial was done it was not registered in ethics committee as per Institutional Ethics committee guidelines, hence Institutional Review Board (IRB) number was not obtained. The study performed in accordance with the principles of the Declaration of Helsinki. Written informed consents were obtained.

\section{Patient consent}

The present work was performed after the patient provided informed consent, and a sincere effort has been made to uphold patient confidentiality.

\section{Supplementary material}

Supplementary Data 1 associated with this article can be found online at https://doi.org/10.5468/ogs.2019.62.5.362.

\section{References}

1. Kim MJ, Park YK, Cho JH. Cotyledonoid dissecting leiomyoma of the uterus: a case report and review of the literature. J Korean Med Sci 2002;17:840-4.

2. Weissferdt A, Maheshwari MB, Downey GP, Rollason TP, Ganesan R. Cotyledonoid dissecting leiomyoma of the uterus: a case report. Diagn Pathol 2007;2:18.

3. Roth LM, Reed RJ, Sternberg WH. Cotyledonoid dissecting leiomyoma of the uterus. The Sternberg tumor. Am J Surg Pathol 1996;20:1455-61.

4. Menolascino-Bratta F, García de Barriola V, Naranjo 


\section{Obstetrics \& Gynecology Science}

Vol. 62, No. 5, 2019

de Gómez M, García Tamayo J, Suarez JA, Hernández Chacón AV. Cotyledonoid dissecting leiomyoma (Sternberg tumor): an unusual form of leiomyoma. Pathol Res Pract 1999;195:435-8.

5. Smith CC, Gold MA, Wile G, Fadare O. Cotyledonoid dissecting leiomyoma of the uterus: a review of clinical, pathological, and radiological features. Int J Surg Pathol 2012;20:330-41.

6. Cramer SF, Patel A. The frequency of uterine leiomyomas. Am J Clin Pathol 1990;94:435-8.

7. Tanaka H, Toriyabe K, Senda T, Sakakura Y, Yoshida K,
Asakura T, et al. Cotyledonoid dissecting leiomyoma treated by laparoscopic surgery: a case report. Asian J Endosc Surg 2013;6:122-5.

8. Anderson MC, Robboy SJ, Russell P. Chapter 15. Uterine smooth muscletumours. In: Pathology of the female reproductive tract. 1st ed. London: Churchill Livingstone; 2002. p.389-414.

9. Gurbuz A, Karateke A, Kabaca C, Arik H, Bilgic R. A case of cotyledonoid leiomyoma and review of the literature. Int J Gynecol Cancer 2005;15:1218-21. 